\title{
Future Postgraduate Choices of First and Final Year Clinical Students in Ghana
}

\author{
Yifieyeh Abiboye Cheduko', Duduyemi Babatunde Moses ${ }^{2,}$,, Kumahor Elikem ${ }^{1}$, Kotoku Eyiram ${ }^{1}$, \\ Moses Monday Omoniyi ${ }^{3}$, Fefemwole Prince ${ }^{2}$, Akwetey Francis ${ }^{1}$ \\ ${ }^{1}$ Department of Surgery, Komfo Anokye Teaching Hospital, Kumasi, Ghana \\ ${ }^{2}$ Department of Pathology, Kwame Nkrumah University of Science \& Technology, Kumasi, Ghana \\ ${ }^{3}$ Department of Sports \& Exercise Science, Kwame Nkrumah University of Science \& Technology, Kumasi, Ghana
}

Email address:

tundeduduyemi@gmail.com (B. M. Duduyemi)

${ }^{*}$ Corresponding author

\section{To cite this article:}

Yifieyeh Abiboye Cheduko, Duduyemi Babatunde Moses, Kumahor Elikem, Kotoku Eyiram, Moses Monday Omoniyi, Fefemwole Prince, Akwetey Francis. Future Postgraduate Choices of First and Final Year Clinical Students in Ghana. Central African Journal of Public Health. Vol. 4, No. 1, 2018, pp. 7-11. doi: 10.11648/j.cajph.20180401.12

Received: December 19, 2017; Accepted: February 11, 2018; Published: March 6, 2018

\begin{abstract}
Since the establishment of the Ghana College of Physicians and Surgeons in 2003, revived interest in postgraduate medical education has led to an increase in specialists in medicine, surgery and related disciplines. While this ongoing process is laudable, the number and variety of specialists are not yet commiserate with the health needs of the population. Semistructured questionnaires (340) were administered to consenting first and final year clinical students of the School of Medical Sciences, Kwame Nkrumah University of Science and Technology, Kumasi, Ghana during the final semester of the 2014 academic session. The questionnaire was based on anecdotes and focused group discussions on the issue of career choices and consisted of sections inquiring about the demographics, general career intentions and postgraduate aspirations of the respondents. Three hundred and fifteen (92\%) out of 340 responders completed the questionnaires adequately; with 197 and 118 first and final year students respectively in M: F ratio of 1.23:1. All our responders were aged 20-25 years. Majority desired postgraduate specialization (86.7\%); and Surgery (43.5\%) and Obstetrics \& Gynaecology (5.38\%) were the most and least favoured specialties respectively. About $74 \%$ of our responders were influenced by personal interests $(p=.01)$ irrespective of gender or year of study. Surgery is the most preferred postgraduate specialization in our study and most of the students were influenced by personal interest.
\end{abstract}

Keywords: Clinical Students, Postgraduate, Training, Subspecialties

\section{Introduction}

Since the establishment of the Ghana College of Physicians and Surgeons by an Act of parliament on the 28th January 2003, revived interest in postgraduate medical education has led to an increase in specialists in medicine, surgery and related disciplines. While this ongoing process is laudable, the number and variety of specialists are not yet commiserate with the health needs of the population. The ratio of 1 doctor to 10,053 patients falls short of that recommended by the World Health Organization (WHO) [1]. Knowledge of the factors responsible for the post graduate choices that medical graduates make would help to inform policy formulation, afford curricular adjustments and foster targeted mentoring based on identified trends [2].

Factors influencing the specialties that new medical doctors choose have been evaluated and revaluated extensively in Europe and North America [3, 4, 5, 6]. Fewer studies have emanated from Asia [7,8]. A small study in Malawi and 2 larger ones in South Africa have given some perspective to the determinants of the choices fresh graduates from African medical colleges make [9, 10, 11]. The findings were varied, thus rehearsing the need for the generation of local data to cater for our peculiar circumstances. Most statements about the career preferences of medical graduates in Ghana are anecdotal. 
In Ghana, undergraduate medical training lasts for 6 years, followed by a 2-year internship in the major specialties of Internal Medicine, Surgery, Obstetrics and Gynaecology and Paediatrics. We opined that financial considerations, family background, exposure to specific clinical specialties and the presence of mentors play strong roles in the postgraduate choices of medical graduates in Ghana. Our study aimed at ascertaining to which extent, if at all, any of these or other factors influence medical students in Ghana to choose future career paths.

\section{Methods}

A cross-sectional study was designed. Semi-structured questionnaires (340) were administered to consenting first and final year clinical students of the School of Medical Sciences, Kwame Nkrumah University of Science and Technology, Kumasi, Ghana during the final semester of the 2014 academic session. The questionnaire was based on anecdotes and focused group discussions on the issue of career choices and consisted of sections inquiring about the demographics, general career intentions and postgraduate aspirations of the respondent. This last section included questions about the factors which may have played a role in the respondent's current intentions and aspirations.

Collated data was analyzed using SPSS version 23.0.

\section{Results}

Three hundred and fifteen questionnaires were completed and returned (92\% response rate). Of this, $62.5 \%(\mathrm{n}=197)$ were $1^{\text {st }}$ year clinical students and $37.5 \%(n=118)$ were in their final year. The male: female ratio was 1.23:1 (55.2\% males, $44.8 \%$ - females). Most (87.6\%) respondents were aged between 20 - 25 years. Majority desired postgraduate specialization $(86.7 \%)$ and additional non-medical qualification (78.1\%). The latter desire was higher among males $(83.9 \%, \mathrm{p}=0.18)$ and final year students $(83.9 \%$, $\mathrm{p}=0.50$ ). Surgery was the most frequently chosen field of specialty (43.5\%). Obstetrics and Gynaecology was least favoured by the students $(5.39 \%)$. See figure 1 .

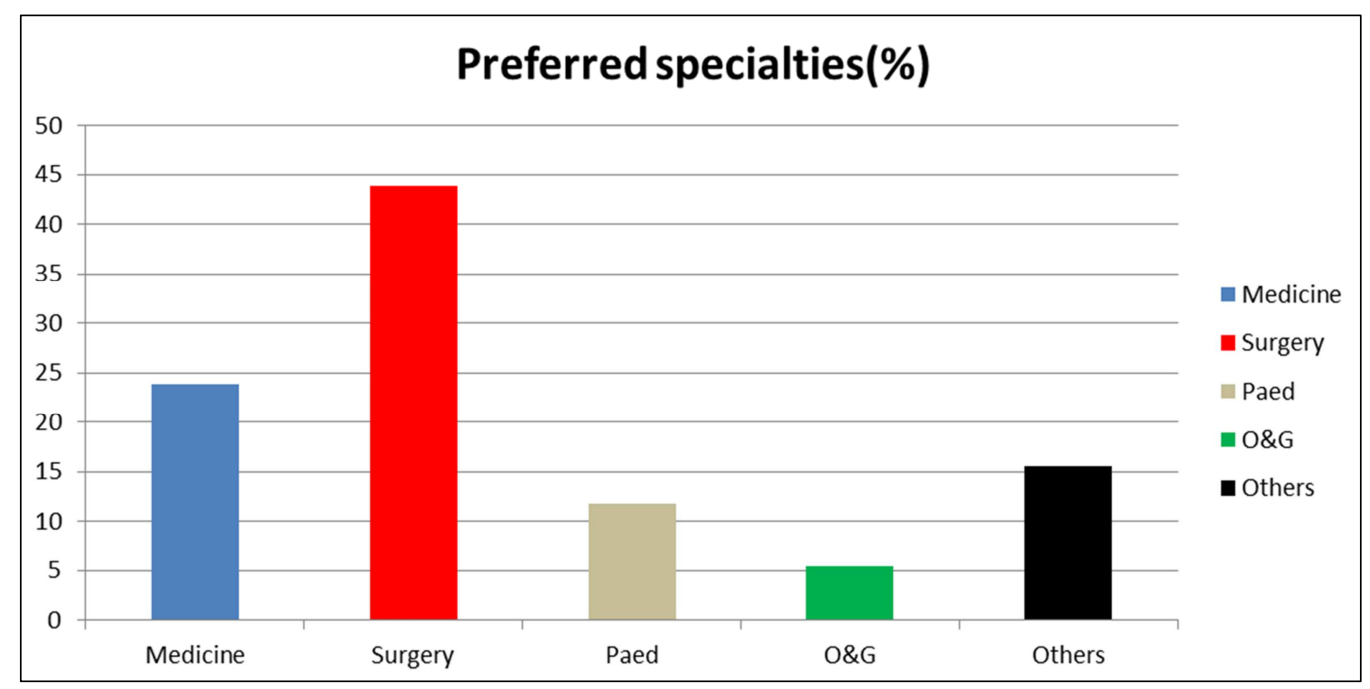

Figure 1. Preferred specialty (\%).

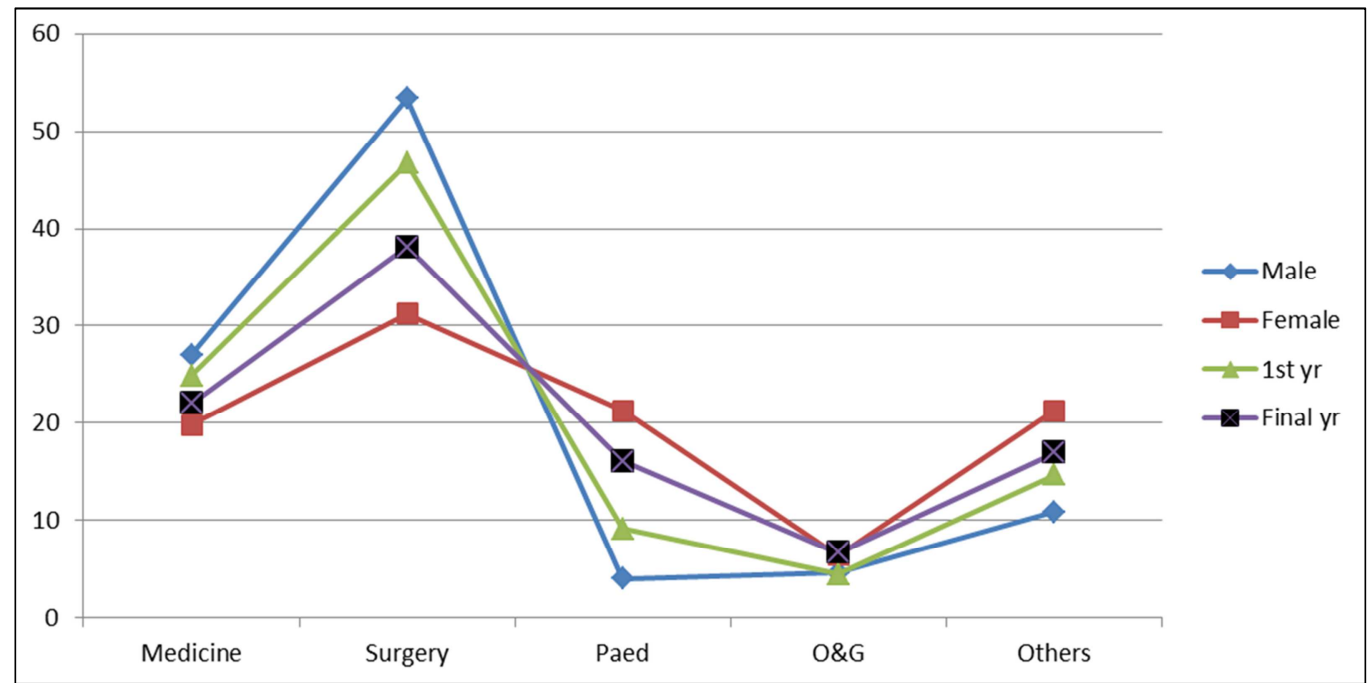

Figure 2. Preferred specialty (\%) by sex and year of study. 


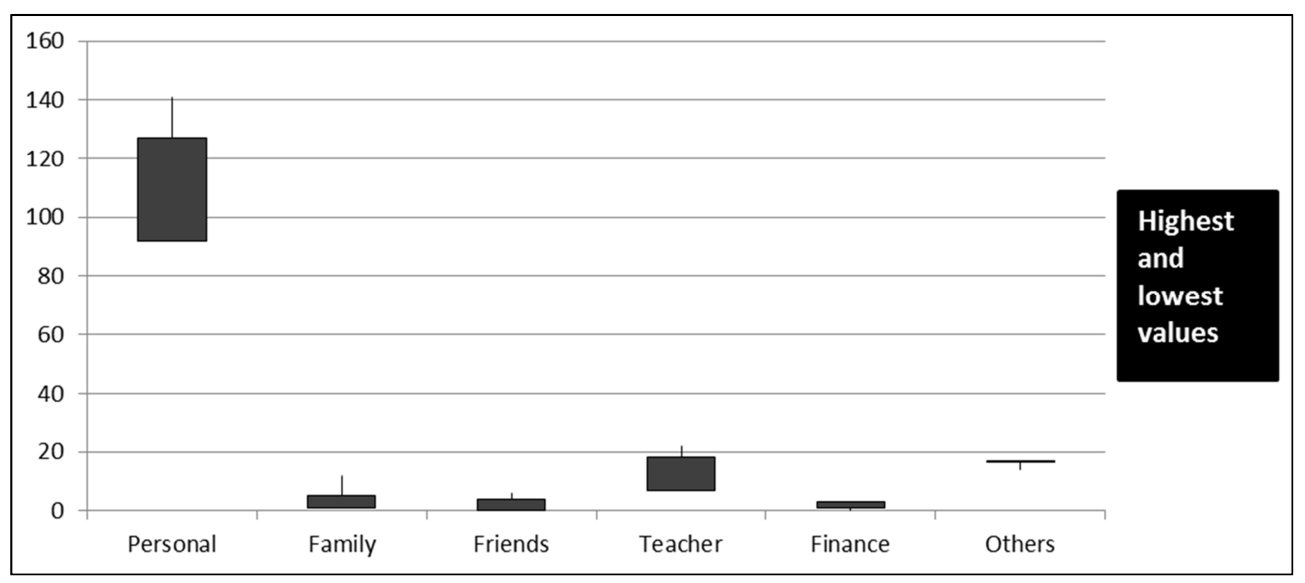

Figure 3. Reasons for choice of specialty.

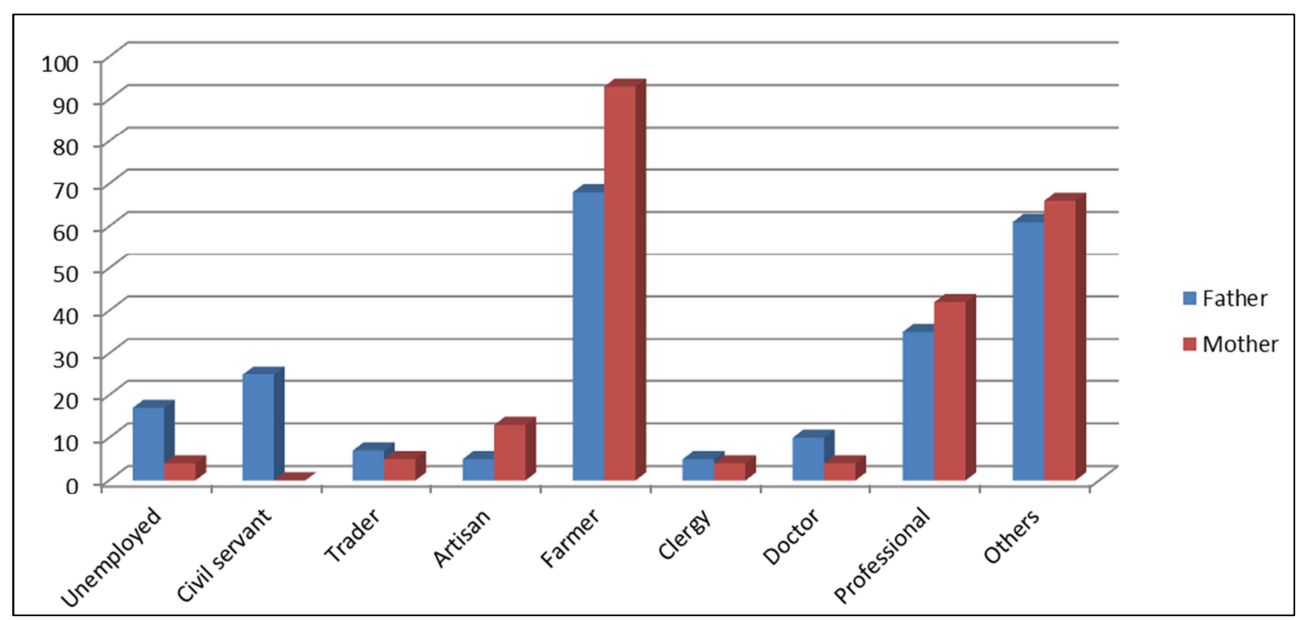

Figure 4. Parental occupation of those influenced by personal reasons.

Paediatrics was the least selected specialty by males, while internal medicine was the second most favoured choice irrespective of sex and year of study. Figure 2 displays the career preferences made by sex and year of study.

Seventy-four percent of respondents stated that personal interests had influenced their choices $(p=.01)$. This factor cuts across the sexes and year of study. Farming was the most frequent occupation of parents of all the respondents influenced by personal interests. Figure 3 depicts the factors (by plot area) that the respondents indicated had influenced their chosen postgraduate path. Figure 4 shows the parental occupation of the students who were influenced by personal interests.

\section{Discussion}

The specialties popular as postgraduate career paths among clinical medical students in Kumasi, Ghana have been uncovered by this study. Surgery is no longer just the anecdotal career choice of these medical students as it was the most frequently chosen specialty whether they were males, females, or were in their first or final clinical year. Most students also desired an additional degree in a nonmedical field despite obtaining an integrated intercalated degree in Human Biology on graduation. Optional intercalated degrees have been found to be associated with the selection of non-clinical fields for postgraduate specialization [14]. In fact, in the US, specialization in clinical fields has decreased over time [17]. Clinical fields are attractive to most of our students.

In South Africa, Azu et al also discovered that surgery was the most preferred specialty of interest (53\%) for postgraduate studies amongst the first year (preclinical) students of Nelson R. Mandela School of Medicine, University of KwaZulu-Natal [9]. There was a female preponderance in that study population. Lefevre $\mathrm{JH}$ et al found, in a national survey of medical undergraduates in France, that surgical and medical specialties were most frequently (47\%) selected [4]. Although Surgery and Internal medicine were the top two specialties of choice by both sexes in our study, females were still more likely to pursue a career in Paediatrics and other specialties apart from O\&G. This departs from the obvious gender difference in career preferences reported in other studies where most females preferred Paediatrics and O\&G to Surgery and Internal medicine [5, 12, 18, 19]. Males were least likely to pursue a career in Paediatrics which agrees with findings in other studies [13]. Our findings may mean our circumstances are peculiar or that the rising number of female medical students is also beginning to direct females towards specialties that 
were traditionally male dominated $[12,20]$.

Both first and final clinical year students also preferred Surgery and Internal medicine above the other specialties. Final year students were however relatively less likely to choose Surgery and more likely to choose Paediatrics as future careers in comparison to their first year counterparts. Students are known to change their minds about future postgraduate choices as they progress in their studies [15]. This may be because of better exposure to other specialties thus expanding their scope of selection.

Personal and self-interests was the predominant factor of influence selected by the majority of respondents. This was similar to a study by Azu et al [9]. Our results demonstrate that this pattern was irrespective of sex and year of study. Surprisingly, family and teachers played little roles in the career choices of our medical students. Although not explored explicitly in our study, other studies identified some other factors. Quality of life, work-life balance and flexibility of training were important issues affecting choices amongst UK graduates $[5,15,16]$. Job satisfaction and income were the foremost reasons in India and some parts of the US [7, 21]. In China, the increasing desire for research and not just clinical positions by medical graduates is thought to be driven by the lure of better opportunities for international collaboration [8, 22].

Parental occupation did not appear to have influenced the career aspirations of the respondents. In fact, most of the parents were farmers. In China children of doctors and professionals were more likely to pursue postgraduate specialization [8].

\section{Conclusion}

Our study has assessed how medical students view specialties as career prospects and the factors that have contributed to the making of their choice. Encouraging subspecialization in Surgery early on may be of benefit since it is the most favoured career path.

The findings in this study should be generalized to all medical students in Ghana with caution due to the fact that some studies have shown that career preferences tend to differ from one medical school to another ${ }^{13}$. Further studies which would, first, test the popularity or otherwise of additional clinical and non-clinical specialties (not specifically listed in this study) and then explore other possible determinants the choices of career are desirable to better prepare for the career coaching of medical students.

\section{References}

[1] World health organization - Health workforce: Achieving the health-related MDGs. [Data base on the internet].

[2] Michael J. Peluso, Janet P. Hafler Medical Students as Medical Educators: Opportunities for Skill Development in the Absence of Formal Training Programs Yale J Biol Med. 2011 Sep; 84 (3): 203-209.
[3] Jeffe DB, Whelan AJ, Andriole DA Primary care specialty choices of United States medical graduates, 1997-2006. Acad Med. 2010 Jun; 85 (6):947-58.

[4] Lefevre JH, Roupret M, Kerneis S, Karila L. Career choices of medical students: a national survey of 1780 students. Med Educ. 2010 Jun; 44 (6):603-12.

[5] Yusur Al-Nuaimi, Ardeshir Bayat, Gus McGrouther. Modernizing medical careers and factors influencing career choices of medical students British Journal of Hospital Medicine, March 2008, Vol 69, No 3:163-166.

[6] Leduc N, Vanasse A, Scott I, Scott S, Orzanco MG, Maman Dogma J, Abou, Malham A. The Career Decision-Making Process of Medical Students and Residents and the Choice of Specialty and Practice Location: How Does Postgraduate Medical Education Fit In? Members of the FMEC PG consortium; 2011.

[7] Smitha Bhat, Landric D'souza, Jeffrey Fernandez Factors Influencing the Career Choices of Medical Graduates Journal of Clinical and Diagnostic Research. 2012 February, Vol-6 (1): 61-64.

[8] LingBing She, BingLi Wu, LiYan Xu, JianYi Wu, PiXian Zhang, EnMin Li. Determinants of career aspirations of medical students in southern China. BMC Medical Education 2008, 8:59.

[9] Azu OO, Naidu E, Naidu J. Choice of speciality amongst firstyear medical students in the Nelson R. Mandela School of Medicine, University of KwaZulu-Natal. Afr J Prm Health Care Fam Med. 2013; 5 (1), 513-519.

[10] Nicola Bailey, Kate L Mandeville, Tim Rhodes, Mwapatsa Mipando. Postgraduate career intentions of medical students and recent graduates in Malawi: a qualitative interview study. BMC Medical Education 2012; 12:87.

[11] Shumba A, Naong M. Factors Influencing Students' Career Choice and Aspirations in South Africa. J Soc Sci, 2012; 33 (2):169-178.

[12] Goodyear H, Kennedy C, Wall D. Career choices: foundation year trainees' views on careers advice and information. Br J Hosp Med 2007; 68 (4): 211-15.

[13] Goldacre MJ, Turner G, Lambert TW. Variation by medical school in career choices of UK graduates of 1999 and 2000. Med Educ 2004; 38: 249-58.

[14] McManus IC, Richards P, Winder BC (1999) Intercalated degrees, learning styles, and career preferences: prospective longitudinal study of UK medical students. BMJ 319: 542-6.

[15] Lambert TW, Davidson JM, Evans J, Goldacre MJ (2003) Doctors' reasons for rejecting initial choices of specialities as long-term careers. Med Educ 37: 312-18.

[16] British Medical Association (2006) BMA Cohort Study of 2006 medical graduates. First Report. British Medical Association, London.

[17] Jeffe DB, Andriole DA, Hageman HL, Whelan AJ. The changing paradigm of contemporary U.S. allopathic medical school graduates' career paths: analysis of the 1997-2004 national AAMC Graduation Questionnaire database. Acad Med, Washington: 2007; 82:9. 
[18] Buddeberg-Fische B, Klaghofer R, Abel T, Buddeberg C. Swiss residents' speciality choices - impact of gender, personality traits, career motivation and life goals. BMC Health Serv Res. 2006.

[19] Fukuda Y, Harada T. Gender differences in specialty preference and mismatch with real needs in Japanese medical students. BMC Med Educ. 2010.

[20] Breier M, Wildschut A. Changing gender profile of medical schools in South Africa. S Afr Med J. 2008.
[21] Newton DA, Grayson MS, Thompson LF: The variable influence of lifestyle and income on medical students' career specialty choices: data from two U.S. medical schools, 19982004. Acad Med 2005, 80:809-814.

[22] Lam TP, Wan XH, Ip MS: Current perspectives on medical education in China. Med Educ 2006; 40 (10):938-939. 